\title{
Engaging blended learning students: an evolving approach to engaging students through the VLE
}

\section{Steve Hogg}

Southampton Solent University, UK

\section{Andrew Doig}

Southampton Solent University, UK

\section{Abstract}

Students taking part-time, distance or blended learning units who are also in employment face high commitment demands of work, life and family in addition to their study. They do not have time to face the additional challenge of making sense of difficult to access learning materials. These students are also often highly discerning and will talk with their feet - failing to complete units that don't engage.

At Southampton Solent University (SSU), we recognise the need to make online or blended units accessible and supportive. In order to engage students on these, we have developed a set of institutional standards for online course development that aim to make materials intuitive, easy to access, clearly introduced and well signposted. The standards also identify minimum levels of support and collaboration required in order for students to feel both engaged in and to gain maximum benefit from the learning processes.

At the same time we have established a Flexible Delivery Development and Support Team which collaborates with academic staff in course planning, writing and delivery. This team works with tutors to achieve the standards while aligning learning outcomes and assessment with online and blended learning activity.

This paper was presented in draft form as an interactive workshop at the ALDHE 2011 conference in Belfast.

Keywords: online; distance; blended learning; engagement; students in employment; virtual learning environment; quality standards. 


\section{The discerning adult learner}

As an institution, Southampton Solent University (SSU), like many other providers in the sector, is increasing provision of courses aimed at part-time, mature, often professional learners delivered through distance and blended learning. In regard to blended learning, according to MacDonald (2008, p.2), 'the term is commonly associated with the introduction of online media into a course or programme, while at the same time recognising that there is merit in retaining face-to-face contact and other traditional approaches to supporting students. It is also used where asynchronous media such as email, forums, blogs or wikis are deployed in conjunction with synchronous technologies, commonly text or audio'.

Blended learning at SSU is characterised by the balanced application of learning technology building on sound pedagogic practice with the purpose of enhancing the learning experience of the student and offering increased flexibility in how, when and where they study. The online aspects of this blended learning are enabled through the use of the University's Moodle-based Virtual Learning Environment (VLE).

Blended learning courses are not entirely new to the University. Doig (2011) conducted a survey of academic staff delivering existing blended learning courses at SSU, from which some recurring characteristics of this new constituency of student were identified. These students:

- Are in work.

- Are in a variety of industries.

- Have reached a 'peak' level in their profession and so require further qualification to move up or on.

- Have a very specific first degree.

- Often have young families.

- Have limited available time.

- Have not been in formal education for some time.

HE institutions are undoubtedly going to need to find effective ways of providing learning opportunities to adult learners meeting these characteristics. In 2008, Bill Rammell, then Minister of State for Higher Education, speaking to the Open University's Student's 
Association Conference said, 'We're going to need to get many more mature people into higher education over the next decade...For most of the 171 higher education institutions in this country, the consequences of all that are going to be very challenging. They're going to have to enter what is, for most, very unfamiliar territory: dealing with older, possibly more demanding and certainly more discerning students' (Rammell, 2008, online).

When presenting on their experience of running a Masters-level degree via blended learning at SSU, Patrick and Newell (2009) shared an impactful quotation from one of their students, 'one point about myCourse [the VLE] is, that's effectively our university, that's our lives'. The VLE is central to the learning experience of the blended and distance learner, and they will demand that the VLE is put to effective use to enable their learning. One student on an SSU blended learning Masters commented, 'The needs and study patterns of mature students - and those who are distance learning - are, I would suggest, very different from traditional undergraduates. Time is a precious commodity and therefore systems/portals etc. must be quick and easy to use'. The VLE is central to the learning experience of the blended and distance learner, and it can be anticipated that they will demand that the VLE is put to effective use to enable their learning.

Further, as universities strive to find new and more efficient income streams and to attract new learner constituencies it is likely that the balance between blended and distance learning will move more towards distance. This is already occurring at SSU, where we have seen demand for entirely distance provision increase against blended delivery because of students' inability to take on the commitment of the face-to-face hours. As Liu, (2008), points out distance learning, 'is not bounded by space and time', which suggests that it becomes more accessible for those who are limited in their availability to be in place at a fixed time. Liu also suggests that in modern contexts, while it allows teaching to come out of the classroom, 'distance learning also needs to use technology'. It is important to bear in mind that the application of this technology must keep at its heart the student experience. As one SSU blended learning student says, 'Because you aren't on campus all the time, you have to have very clear information about what you are required to learn. You also have to have a very good environment where you can still communicate with your peers, so that the on campus environment is essentially replicated virtually'. 
This student's words strike on one particular issue that impacts the student experience when institutions move towards increased distance learning as stated by Croft et al. (2010, p.1), 'the physical and temporal separation of tutor and student, and between students themselves, can lead to feelings of isolation'. With this in mind, it is imperative to strive to find ways to create a sense of community and a supportive environment through the online platform, moving towards communities of practice.

Wenger (1998) criticised established attitudes to learning: learning viewed as an individual process taking place in a structured traditional learning environment (classroom) that ignores the social aspect of learning that takes place in communities which he calls 'communities of practice'. For Wenger, the social aspect is of critical importance in the whole learning process and his work is focused on highlighting the need for more emphasis to be placed on learning as social participation rather than an activity done in isolation. Wenger's ideas if applied in online environments can provide opportunities for online networks to be created; these networks can be both formal, such as in the case of a moderated group discussion, or informal and non-moderated, created organically among participants.

This effort to create networks is clearly appreciated by our students. Two current distance learners at SSU have said, 'There's definitely camaraderie between all the different students on the course, and it sort of encourages people. Everyone encourages each other', and, 'I've found it quite refreshing to think that you're not this lone individual, you've actually got the resources not only of the university but of your cohort'.

However, there are many challenges in making e-learning engaging and a true learning experience. This is reflected in the attrition rates commonly experienced in online distance courses. Betts (2009, online) reflects the recent state of online attendance in the USA: 'While online enrolments are predicted to increase, attrition still remains higher for online programs than on-campus programs. Online attrition rates are often cited within the literature as $20 \%$ to $50 \%$ '.

Through consideration of these factors, we have been led to ask the questions: How do you create a learning experience within the VLE that is every bit as good as attending a great lecture or seminar? How is engagement maintained while bringing the student to feel 'I really learned something there'? 


\section{A cycle of reflection and improvement towards better e-learning}

As a university lecturer it is a requirement nowadays to use the institutional VLE to support undergraduate and postgraduate student learning. At SSU the students recognise the value and convenience of having materials available that they can access at any time. For example, one student commented on the online content from Steve Hogg's unit on Online Media, 'I can honestly say that without Steve's tutorials that he has posted onto myCourse I would have never of [sic] worked out where to start'. Conversely, it is our experience that when there are limited VLE materials for a given unit students will not be slow to complain. Recent blended learning course feedback has highlighted that students are very conscious when some units provide clearly structured study, while others have barely anything. One described the effect of this as, 'It's all just a little disjointed and annoying'. It is important for us to recognise the student voice and allow it, at least in part, to lead on the spread of the VLE and its place in the student learning experience.

However, it is still the case that the majority of materials contained within the institutional VLE are PowerPoint slides and text documents. It is used regularly and effectively as a notice board, and often with some level of forums and discussion threads. To go beyond this standard use of the VLE takes commitment from the course developer, as well as some knowledge of how to make best use of the tools provided through the platform.

A process of reflection and change for improvement greatly benefits the academic and concurrently the students in their experience of teaching and learning via the VLE. The importance of reflection and its role in professional life has been highlighted by Schön (1995). For Schön, reflection-in-action is critical for the practitioner to develop their competency in their profession. Placing reflection in the context of teaching practice, Biggs (1999, p.6) says, 'a reflection in a mirror is an exact replica of what is in front of it. Reflection in professional practice, however, gives back not what it is, but what might be, an improvement on the original'. Extending this reflection-in-action to use of the VLE and other learning technologies, academics are presented with a great opportunity to enhance the student experience by making the best of both environments, the classroom and the online environment (Garrison, 2001).

Steve Hogg, while Head of Learning Technologies at SSU, also teaches for the Faculty of Creative Industries and Society. His technical expertise is able to inform his teaching. 
However, it is also very much the case that through his teaching, Steve has been able to develop his understanding of effective online and blended course delivery. His unit development and the development of his online teaching provision have benefited from a cycle of reflection that he now describes:

As a tutor I have evolved my own unit in the VLE. I have been constantly reviewing and improving over the past four years. A large part of this has been my evolving understanding of how to best use the Moodle pages of our myCourse VLE to best engage my students.

This reflective and progressive development of e-learning materials and practice is commented on by Almpanis et al. (2010), as most online tutors begin at a minimum requirements level of engagement, developing, through successive iterations towards more fully developed and engaging online learning resources. Similarly, Salmon (2011) presents her five stage model as a set of steps or levels that the online tutor (or 'emoderator') should aim to lead their students through, while acknowledging that 'each stage calls for different e-moderating skills' (p.32), and hence tutors will need to take time to gain the skills and be able to moderate to this level.

Again, from Steve Hogg:

In the first iteration, I used Moodle as seems first and most easily usable. The disadvantage was that I ended up with a great long list of resources running down my home page. Another challenge was that Moodle generates numbered boxes. A logical first approach was to have a box for each week in the semester, ending up with 12 boxes, each with its own list of items.

A list of great materials for the students to find and explore is very useful when you are in the classroom to point them in the direction of the relevant item and explain, 'What are we clicking on?', but this may not work so well for students who either don't turn up for class so often or don't have so many scheduled classes. On reflection I wished to make things much more intuitive.

In this concern for the intuitive comprehensibility of the online course content, Steve would seem to be hoping to 'scaffold' his students' introduction to their online learning in much 
the way that Salmon uses the term in her book on E-moderating (2011, p.33 initially and then later giving a whole chapter to techniques to scaffold students e-learning, pp.193197).

At the next stage, I replaced the 12 week list with a box each for the big topics and a box for everything else; so down to three boxes but maintaining the same size list.

Following this, I discovered the Moodle book format. Adopting this lets me have a narrative voice in the VLE, putting activities and resources into context. In the onscreen text, I can say why something is important and relevant.

The book format has certainly had impact in the Moodle user community. The Open University's extensive, and freely available, Open Learn resources are presented in the book format (or a version of it at least), its structure of indexed content pages allowing for presentation of extensive, textual, narrative content suited to the standalone nature of these resources. One Moodle developer shares the following list of advantages of the book format: 'chunk content, simplify delivery, ease of access, ease of editing' (Moore, 2011, online).

Steve continues:

With further reflection, I realised that, as a teacher of online media, I wanted to use it to support my students' learning. This came in the form of short video tutorials that I created using cheaply available screen recording software.

This was a big success with the students and had several advantages:

1. As a substitute teaching for absent students.

2. As review materials for struggling students.

3. As preparation for students pushing ahead.

What was interesting about the video tutorials was that I was putting myself into the learning object. It was acting as an extension of the classroom contact and I also felt that having a context and a narrative in the online material was important. 
Further, the combination of the narrative text and video content means that students with different preferences or approaches to learning have equal learning experiences.

The impact of video content on tutor presence in online materials has been noted by Jones et al. (2008, online): 'We evaluated student perceptions relating to the significance of producing an introductory video to introduce the instructor to students in both a fully online course and a hybrid course. From the results of this study, we concluded that introductory videos can help to establish the instructor's teaching presence with the students, regardless of the method of delivery of the course'.

Steve concludes:

The process described above has seen a consistent rise in levels of student satisfaction with my unit:

- $81.6 \%$ - Student Unit Evaluation Survey 2008

- $90.6 \%$ - Student Unit Evaluation Survey 2009

- $96.8 \%$ - Student Unit Evaluation Survey 2010

It has also led to extremely positive student comments, such as: 'The online tutorials have been priceless and I have recommended them to so many people who felt stuck like I did and they have had the same helpful effect every time so now even I am passing on knowledge I have learnt which is a great feeling'.

The key to the process that Steve describes above is that it is a developmental one that has achieved success through reflection over an extended period of time and experimentation in order to achieve best results. Variations of this process are undergone by active and considerate academics and support staff across the University. Examples of this are particularly found among staff taking the University's Postgraduate Certificate in Blended Learning. One student of this course comments, 'The reflection that is core to the activity of the PG Cert allowed me to identify major elements of my online curriculum that I could revise and greatly improve through experimentation, evaluation and choices informed by theory'. Similarly, in his work helping academic staff to develop online content for distance and blended learning courses, Andrew Doig observes that conscientious staff 
are always eager to revisit and improve their online units with each successive iteration, rather than resting on their laurels of extant and returnable unit content.

\section{Building a concept of high-quality course content}

In 2009, SSU was awarded funding from the Higher Education Funding Council for England (HEFCE) and created a Strategic Development Fund to run across three years. Under this funding and the Strategic Development Programme (SDP) that resulted from it, SSU's e-Development Centre successfully proposed the creation of a Flexible Delivery Development and Support Team (FDDST). The objective of this team is to bring together learning technologists, instructional and media developers along with academic staff to work on the development of high-quality course content for online blended and distance learning courses (and build on the good work to date carried out in providing technologyenhanced learning and blended learning within the University).

One of the first activities of the FDDST was to conduct an informal survey of the e-learning landscape within, and beyond, the Higher Education (HE) sector in order to build a concept of what we mean by high-quality in relation to online courses. Individual team members reviewed the provision of other institutions to find exemplars of components that they felt contributed positively to a student's ability to engage and learn through the online teaching content, while also reflecting on successful projects they had been involved in. This survey was unstructured, as in it did not depend on fixed criteria of what defines highquality but rather was based on the received knowledge of our internal team of e-learning experts drawing comparisons and conclusions on what would be achievable through our available human and technical resources.

The survey of external providers was advantaged by the move towards open education resources among institutions such as the Open University (OU) and the University of Nottingham in the UK, MIT and Stanford in the USA, as well as the wealth of other elearning provision openly available, such as the BBC Academy. A variety of impactful features were identified, for instance: 
- The OU makes excellent use of the Moodle book, providing extended narrative delivery of content and enabling a tutor presence, while also embedding various kinds of learning activities aimed at student engagement within the materials. As previously mentioned, this also concurs with Steve Hogg's introduction of the Moodle book into his own unit development. The resulting standalone accessibility of these resources mean that students can use and reuse them as they move towards mastery of the skills presented.

- Stanford University has gone to great lengths to provide a series of video lectures that appear in all of their OER, thus giving a strong sense of university identity, as well as putting faces to the expertise held within the institution. Examples of similar use of online video content within SSU again come from Steve Hogg's teaching resources, as well the project into providing video training resources provided via hand-held devices carried out at SSU by Dr Stewart Bruce-Low and reported in the JISC booklet 'Effective Practice in a Digital Age' (2009).

- Nearly all providers used a consistent presentation of content within the courses or units that they deliver; various features such as learning or communication tools as well as navigation features are presented consistently within the same frames of the web page. This style of consistent content presentation has been experimented with and improved based on user feedback in the SSU project, succeed@solent - an academic skills resource available to students from http://mycourse.solent.ac.uk/succeed.

- Commercial providers such as lynda.com and Adobe TV present very clear introductions to each set of learning materials through high-quality video; highly engaging as well as clarifying the purpose of the resources. Again, introductory videos have been used with positive response from students throughout the succeed@solent materials, and also in all of Steve Hogg's online units.

\section{Arriving at a recipe for success - the Solent Online Learning Standard}

The two processes described above (the improved practice and deeper understanding gained through a continuing process of reflection for improvement, together with the recognition of preferred practice in $\mathrm{HE}$ and beyond) have allowed the FDDST to arrive at a recipe for what we consider to be successful online course delivery. This recipe is a collation of standards and strategies that we believe improve the learning experience for 
students participating in online blended or distance learning courses. It has been the work of the FDDST to collaborate with academic course teams in the attempt to develop courses that meet these standards. We have also carried out a variety of student feedback surveys and usability tests to evaluate the application of these standards and modify the way in which we implement them.

This practice is not unique as other institutions strive to arrive at similar conclusions in order to provide guidance for academic staff. At the INTED 2011 conference, Professor Gordon Suddaby of Massey University presented in his plenary speech on the crossuniversity project in New Zealand 'developing a toolkit to facilitate student engagement through effective blended approaches to teaching and learning' (Suddaby, 2011, online). One of the key outcomes of this project is a 'Blended Learning Course Review Rubric' (Suddaby, 2011, online) that describes components of baseline, effective and exemplary practice across a range of areas relating to the delivery of blended learning courses. Similarly, California State University (2011) publishes via its website a 'Rubric for Online Instruction' that also categorises course design components under the same three standards across areas such as 'Learner Support \& Resources' and 'Online Organisation \& Design'. It is undoubtedly the case that a number of other institutions are looking to establish similar standards in order to assure the quality and effectiveness of online distance and blended learning courses.

In November 2011 we attended a workshop run by the JISC-funded projects SusTEACH and Virtually Sustainable which looked at 'Best Practice Criteria for Sustainable ELearning'. This workshop was very much aimed at opinion sharing and gathering, rather than dissemination, and through this we have become involved in the process of establishing criteria which can be used at an institutional level to try to establish best practice for e-learning in the categories of economic sustainability, pedagogic sustainability and environmental sustainability. The outcomes of this process will have direct impact in our own work.

We have chosen to call our collation of elements the 'Solent Online Learning Standard'. This term has been applied usefully at an institutional level to suggest a set of standards or principles that all course developers and facilitators can aim to achieve. These standards are also currently in the hands of SSU's Academic Services Department with the intention of establishing them as SSU Policy as regards to provision of online distance and blended 
learning resources via the University's new, professional learner-orientated VLE, Solent Online Learning (SOL).

The current elements of the Solent Online Learning Standard are illustrated below:

\section{Figure 1. Southampton Solent University 'Solent Online Learning Standard' for} Online and Blended Learning.

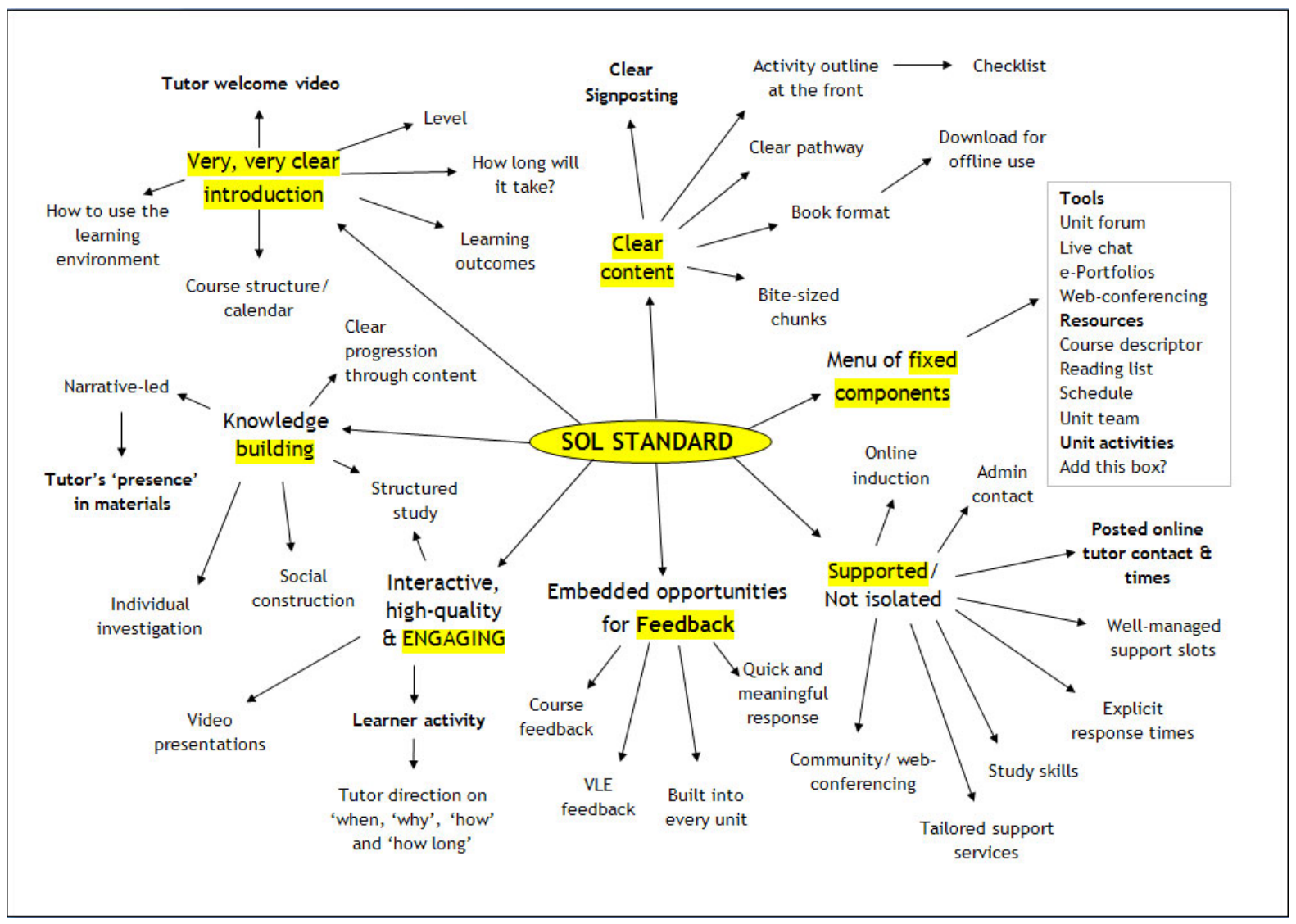

While elements of the initial application of our standards within SOL led to some negative response (for instance students reacted negatively to the use of the book format until we began providing them with task checklists on the first page of each book), recent feedback from students participating on courses delivered via this platform has been extremely positive. One student stated: 'Solent Online Learning has definitely been a very important tool to help me study while I work', while another student commented: 'I like the fact that it is simple. I like the fact that it's not too complicated, and I think that whoever developed it, developed it with people in mind, knowing that not everyone will have a higher knowledge in computing'. One other encouraging comment was: 'The visual aspects of the online unit are very clear. You can find everything really easy and all the information needed is provided in the right areas. My first impressions on the online unit were very surprising. It's 
interesting how there is a welcoming video which will help the students realise who the unit leader is and who to contact with any questions'.

The success of the SOL approach has been evidenced in extremely good retention rates in the initial courses run within the environment (accepting that a variety of other factors will be in play for this effect, not least of which has been the very high level of support provided by academic staff to the students). The first course run in SOL was the MA in Business Studies. For the initial period of this course, September to December 2010, the first year cohort had no withdrawals, the first time this had occurred in the several years the course has been running. The MSc in Shipping Operations, which began in June 2011 with a cohort of 26 students, has to the date of writing (November 2011) seen only one suspension.

The Solent Online Learning Standard has to be flexible as it evolves. It is understood that new components will be recognised as new courses are delivered and feedback received, as well as that not all components will be applicable to all teaching contexts. We are assisted in this by the work conducted by Almpanis et al. (2010) in developing their Blended and Flexible Learning Framework, which identifies four different designs for blended learning that include varying levels of engagement with learning materials and peers, moving from minimum requirements at design 1 through to mixed individual and group study in design 4. It is our hope that a washback effect will occur, where learning and understanding gained in the application of the Solent Online Learning Standard in the heavily resourced professional learner orientated Solent Online Learning environment can be applied more broadly in the myCourse VLE which is used across the rest of the university's, mainly full time, face-to-face courses. The four designs of the Blended and Flexible Learning Framework should help us to provide design templates aimed at allowing tutors to more easily apply different levels of learner engagement through their online course materials.

\section{A consistent approach}

The intention in developing the Solent Online Learning Standard has not been so much to create any startlingly new practice, but instead it has been the desire to create a more consistent institutional approach on how effective online and blended learning may be 
delivered to our students. It allows us to agree on and endeavour to apply standards across a range of courses in different disciplines and contexts. In order to achieve this, we have needed to implement a new model of support within SSU.

In the past, as is common with support of technology enhanced learning within a large institution, the learning technologist works in a capacity of enabling academic staff members to deliver their VLE content independent of continuous support.

\section{Figure 2. Model of support from learning technologists.}

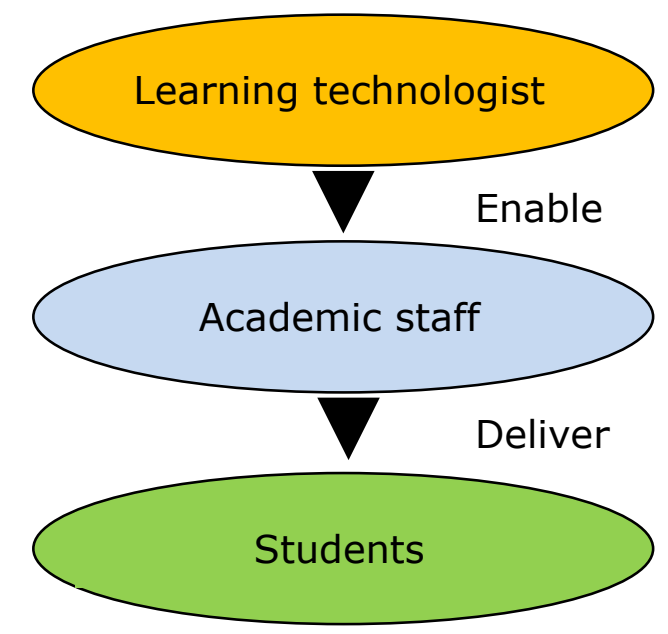

This model has several advantages, but most especially it means that the expert knowledge held by the learning technologists can be shared effectively with a large number of academic staff, who are then able to deliver to an even larger number of students, hopefully creating great impact within the institution. One drawback, however, is that the enabled academics may go on to deliver with varying degrees of success, as the relationship does not necessarily include continued support.

However, with the FDDST, the model works slightly differently, and is very much about the members of the team working collaboratively and continuously with the academics who develop and deliver the technology-enhanced learning experiences via the VLE. 


\section{Figure 3. Model of support from the Flexible Delivery Development and Support} Team.

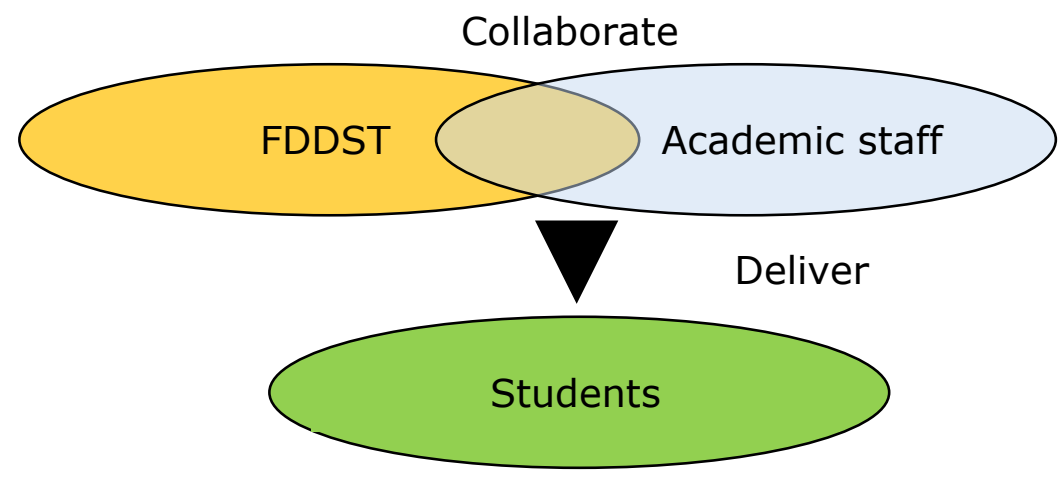

The huge advantage here is that the academic staff, individually or (more usually) as a course team, are continuously enabled and supported by a cross-disciplinary team in order to deliver their VLE content. This means that the output in terms of online course content is maintained at a much more consistent standard, and the provision of online learning is enabled by a much more consistent approach to delivery. The collaboration is conducted with all parties keeping the principles of the Solent Online Learning Standard as the target for development and delivery. The varied input into this collaboration allows opportunity for the recognition of areas of flexibility within the application of the standards. It also means that each course development process can contribute back into the continuing development of the Standards. This model certainly seems to be having positive impact. Georgina Andrews, Head of the Business School at SSU said, 'The support of the Flexible Delivery Team is absolutely vital. It's really important that we have a professional virtual learning environment. We are actually delivering courses to professionals and they expect a very high-quality experience. Without the Team, we wouldn't be able to deliver that'.

One challenge to this model which must be considered is that this level of support is resource hungry in terms of the time spent by the members of the support team. At the moment, this is maintained through funding available from the Strategic Development Programme. It is important that the FDDST, during the duration of the available funding, establish a costing model that weighs the effectiveness of this support against the efficiency of the provision, and hopefully establishes a strategic demand for its longevity. The team is striving to ensure that the quality and scope of the supported courses are such that SSU senior management recognise that the continuance of the FDDST's 
activities is vital for the University's broadening teaching provision and develops policy to ensure the team's sustainability.

\section{Acknowledgement}

Thanks for their support and advice on the writing of this paper need to be extended to Timos Almpanis and Jenny Watson.

\section{References}

Almpanis, T., Patrick, S., Mclellan, R., Dinsmore, C., Faustino, A. and Basuki, W. (2010) 'Proposing a framework for blended and flexible course design', in Kinshuk, Sampson, D.G., Spector, J.M., Isaias, P., Ifenthaler, D. and Vasiu, R. (eds.) Proceedings of the IADIS International Conference of Cognition and Exploratory Learning in Digital Age CELDA2010. Timisoara, Romania 15-17 October. Organised by IADIS International Association for the Development of the Information Society, pp. 263-267.

Betts, K. (2009) 'Online Human Touch (OHT) training and support: a conceptual framework to increase faculty engagement, connectivity, and retention in online education, part 2', MERLOT Journal of Online Learning and Teaching, 5(1), March [Online]. Available at: http://jolt.merlot.org/vol5no1/betts 0309.htm (Accessed: 26 October 2011).

Biggs, J. (1999) Teaching for quality learning at university: what the student does. Buckingham: Open University Press.

California State University (2011) Rubric for online instruction. Available at: http://www.csuchico.edu/celt/roi/ (Accessed: 22 July 2011). 
Croft, N., Dalton, A. and Grant, M. (2010) 'Overcoming isolation in distance learning: building a learning community through time and space', Journal for Education in the Built Environment, 5(1), pp. 27-64 [Online]. Available at: http://ctiweb.cf.ac.uk/jebe/pdf/NicholasCroft5\%281\%29.pdf (Accessed: 26 October 2011).

Doig, A. (2011) 'Online usability for students in employment', INTED Conference 2011. Valencia 8 March.

Garrison, D.R. (2001) E-learning in the 21st century. $2^{\text {nd }}$ edn. Abingdon: Routledge.

JISC (2009) Effective practice in a digital age. Bristol: JISC.

Jones P., Naugle, K. and Kolloff, M. (2008) 'Teacher presence: using introductory videos in online and hybrid courses', Learning Solutions Magazine, March $31^{\text {st }}$ [Online]. Available at: http://www.learningsolutionsmag.com/articles/107/teacher-presence-us (Accessed: 16 February 2012).

Liu, S. (2008) 'Student interaction experiences in distance learning courses: a phenomenological study', Online Journal of Distance Learning Administration, 11(1) [Online]. Available at: http://www.westga.edu/ distance/ojdla/spring111/Liu111.html (Accessed: 26 October 2011).

MacDonald, J. (2008) Blended learning and online tutoring. 2nd edn. Aldershot: Gower Publishing Ltd.

Moore, M. (2011) The best Moodle tools you've never used [Online slide share]. Available at: http://www.slideshare.net/michelledmoore/the-best-moodle-tools-youve-neverused (Accessed: 31 October 2011).

Patrick, S. and Newell, J. (2009) Transition into or back into HE by flexible learning. Conference presentation, Solent Event. Southampton Solent University, September. 
Rammell, B. (2008) Ministerial speech to OU Students' Association Conference. Open University, Milton Keynes 26 April. Available at:

http://www.dius.gov.uk/speeches/rammell OU 280408.html (Accessed: 21 October 2011).

Salmon, G. (2011) E-moderating: the key to teaching and learning online. 3rd edn. Abingdon: Routledge.

Schön, D.A. (1995) The reflective practitioner: how professionals think in action. Aldershot: Arena.

Suddaby, G. (2011) Blending in: exploring blended approaches to student engagement. Available at: http://mro.massey.ac.nz/handle/10179/2180 (Accessed: 22 July 2011). Under Creative Commons License: Attribution Non-Commercial No Derivatives.

Wenger, E. (1998) Communities of practice: learning meaning and identity. Cambridge: Cambridge University Press.

\section{Author details}

Steve Hogg is the Head of Learning Technologies at Southampton Solent University. Steve also teaches Online Media to undergraduate students and Digital Streaming to professional blended learning students for the Faculty of Media, Arts and Society.

Andrew Doig is an Instructional Developer for the Flexible Delivery Development and Support Team at Southampton Solent University. This team collaborates with academic faculty in the development and delivery of online distance and blended learning courses. 